\title{
DEVELOPMENT OF A STEEL-GUIDE CONNECTION METHOD FOR COMPOSITE PRECAST CONCRETE COMPONENTS
}

\author{
Won-Kee HONG, Gyeongju KIM, Chaeyeon LIM, Sunkuk KIM \\ Department of Architectural Engineering, Kyung Hee University, Gyeonggi-do, Korea
}

Received 12 Feb 2014; accepted 01 Jul 2014

\begin{abstract}
Green Frame is a column-beam structure formed by connecting a composite precast concrete beam with a steel connection on the column side. Similar to steel frame construction, the green columns cover 3 stories per unit, and generate vertical and horizontal eccentricities due to construction errors and the gravitational loads of beams. Such eccentricities make it difficult to install the upper floor beams and adjacent frames. This problem not only results in decreased productivity, but also in time delays and cost overrun. The objective of this study is to develop a new steelguide connection method for composite precast concrete (CPC) components after analysing the erection process and structural mechanism to resolve eccentricity issues. The connection mechanism developed in this study resolves these eccentricities and promotes efficient, accurate, and safe construction.
\end{abstract}

Keywords: column-beam structure, composite precast concrete, steel connection, eccentricity, productivity.

\section{Introduction}

\section{Background and purpose}

Green Frame is a column-beam structure formed by connecting a composite precast concrete (CPC) beam with a steel connection on the column side (Lim et al. 2012). Numerous studies have shown Green Frame, which couples the economic efficiency of concrete with the constructability of steel, to be structurally stable environmentally friendly, and to reduce the embodied $\mathrm{CO}_{2}$ by approximately $20 \sim 30 \%$ when compared to existing structural systems (Hong et al. 2009, 2010a, 2010b).

The critical structural work for CPC column-beam structures fabricated by steel joints is that of lifting and connecting (Joo et al. 2012). It was discovered onsite that the CPC columns, covering 3 stories per unit in a manner similar to steel frame construction, generate vertical and horizontal eccentricities in the process of installation due to the gravity loads of the heavy CPC beams and the construction errors. Such eccentricities observed by $30 \sim 50 \mathrm{~mm}$ on site lead to difficulties in the installation of upper floor beams and horizontally-adjacent frames. In such a case, it is necessary to vertically adjust the columns installed using the turn buckle or prop, which leads to delays in the installation of CPC beams and an overall decrease in productivity (Kim et al. 2013). We found that the delay time was a minimum of 30 minutes, and up to 2 hours, which would decrease productivity, followed by the increase of construction cost. The development of a new construction method will ensure both constructability and productivity by resolving these problems.

Lim et al. (2012) proposed a concept which considers the slope of steel sections buried in columns and beams for the quick connection of CPC components, and Kim et al. (2013) suggested a plan for controlling axial eccentricity using a reinforcement plate though no structural characteristics were proposed in detail. Bang et al. (2003) confirmed the issues regarding the method and process of steel erection through a survey of steel structures, and suggested a beam solution involving the connection details of beam; however, no specific engineering evidence was discussed.

The purpose of this study is to develop a steel-guide connection method (SCM) for CPC components, developed after analyzing the erection process and structural mechanism, which resolves the above-mentioned issues. The steel-guide connection method contains the use of steel guide with a pair of L-shaped reinforcement plates to connect CPC beams quickly and safety.

\section{Process}

The study is to be conducted will utilize the following process. First, the problems generated upon installation of the CPC components of the Green Frame are identified. Second, a new Steel-guide Connection Method (SCM) and erection process are proposed to resolve the resulting problems. Third, the structural mechanism of the pro-

Corresponding author: Sunkuk Kim

E-mail:kimskuk@khu.ac.kr 
posed SCM is investigated. Fourth, the slopes of the CPC component connection steels used in commonly designed Green Frames are calculated to efficiently reflect the proposed SCM at the engineering design stages. Finally, the advantages of the proposed method are discussed, and conclusions are made.

\section{Preliminary study}

\subsection{Problem analysis}

As shown in Figures 1 and 5, Green Frame is composed of CPC columns which cover 3 stories per unit with CPC beams installed at each floor. The steel connections of the CPC beams are either T-type or reverse T-type, depending on the structural design.

As in steel frame construction, the primary span of Green Frame is determined by the construction plan, the columns and beams are installed, and the verticality is adjusted. The columns and beams are then installed at the adjacent span to complete the overall structural frame.

When eccentricities of a column are generated during the installation process, the vertical and horizontal eccentricity demonstrated in Figure 2 occurs. Specifically,

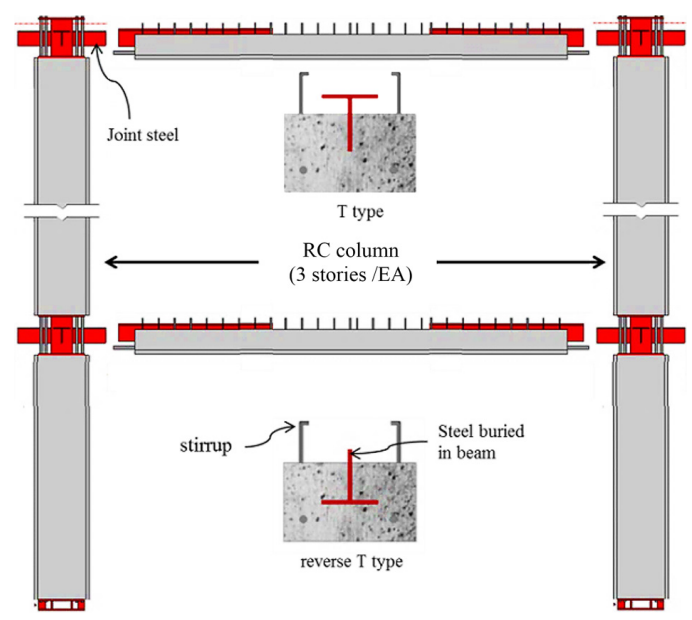

Fig. 1. CPC beams and columns of Green Frame

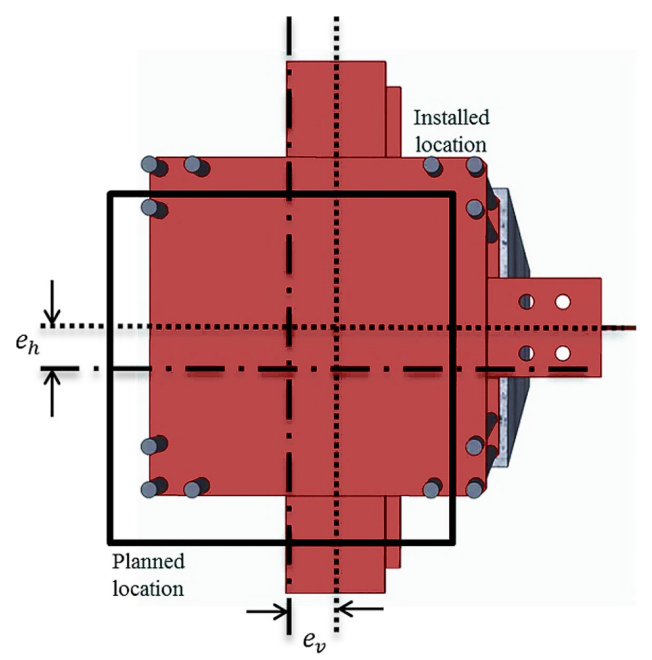

Fig. 2. Eccentricities of a column an axial eccentricity occurs between the column and the beam steels due to construction errors in the columns already installed, Figure 3. Such eccentricity is defined in this study as horizontal eccentricity $\left(e_{h}\right)$.

In addition, as shown in Figures 4 and 5, a column axis eccentricity occurs due to the eccentricities of a column, and is defined as a vertical eccentricity $\left(e_{\nu}\right)$. The vertical eccentricity can be a result of structural behavior, construction error or a combination of both. It was found onsite that the displacement of columns at the second and third floors, as shown in Figure 5, was generated by the gravitational load of the installed beams on the first floor.

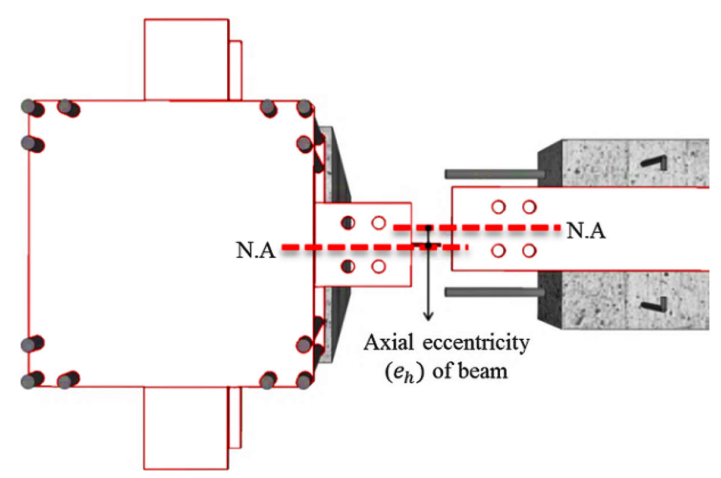

Fig. 3. Axial eccentricity $\left(e_{h}\right)$ of a beam

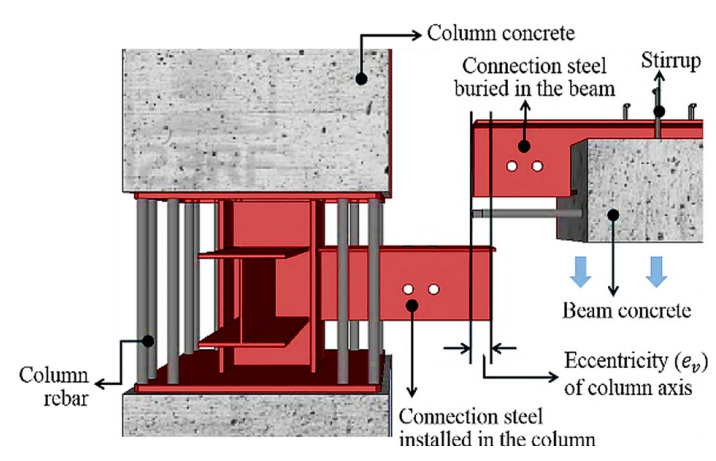

Fig. 4. Eccentricity $\left(e_{v}\right)$ of a column axis

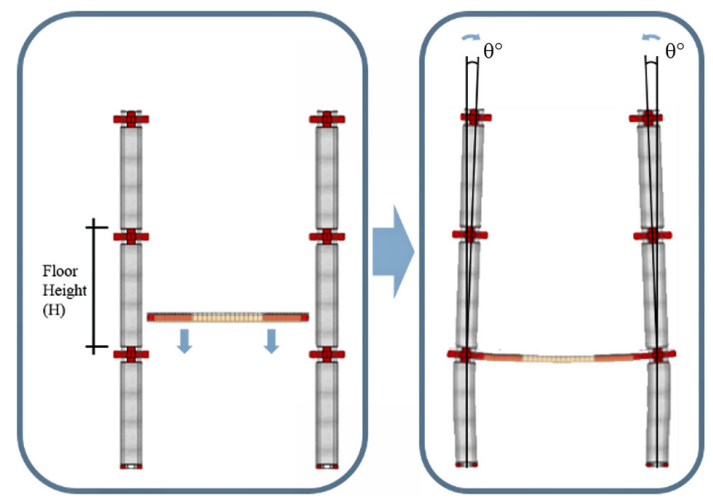

Fig. 5. Eccentricity caused by the gravitational load of a beam 
Though the verticality of the column fabricated with 3 stories per unit was maintained, eccentricities were still generated by the gravitational loads of the CPC beams after installation. Such strain may be trivial initially, but can gradually accumulate with the installation of multiple beams. Installation of beams at the upper floor or adjacent spans, results in the column axis eccentricity shown in Figure 4 (Lim et al. 2012). Readjusting the verticality of previously-installed columns will resolve this issue; however, such additional work creates a loss of manpower and time, and increases cost.

\subsection{Literature review}

The Column-Beam structure can be designed as cast-inplace, precast concrete (PC), structural steel and CPC structures. With the exception of cast-in-place concrete, the remaining structures are applied with the steel connection for member connection, the dry joint, as in mechanical rebar connection, or the mixed dry-wet joint.

The columns and beams of the PC structure temporarily fabricated via sleeve or mechanical connection are connected by rebar and concrete, and their joint performance is relatively weak compared to that of other structures (Seo et al. 2008). As shown in Figure 6, the steel frame is fabricated by the reinforcement plate. Securing the joint strength for stable stress transfer in relation to the connection details is essential for steel connections. If joint strength is not sufficiently considered in the design stage, structural problems may arise in the construction stage (Lee et al. 2011).

In contrast, the CPC columns and beams in Green Frame are initially fabricated by the steel connection, and the fabricated joint is filled with concrete upon slab concreting to form a strong, single body. Thus, Green Frame can supplement the structural disadvantages of $\mathrm{PC}$ and steel structure (Lee et al. 2011, 2012; Lim et al. 2011).

The vertical and horizontal eccentricities mentioned above also occur in existing steel construction. To address these issues, the constructability and productivity of steel connections were improved as compared to existing methods (Kim et al. 2009). Figure 7 shows steel beam installation using a Y-shaped reinforcement plate. This method is composed of a sliding bracket and steel beam, a Y-shaped reinforcement plate, locker and a locker holder. The Yshaped reinforcement plate is designed to reinforce the

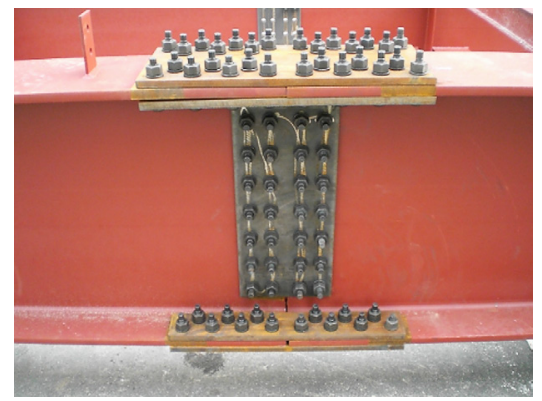

Fig. 6. An example of an existing steel connection

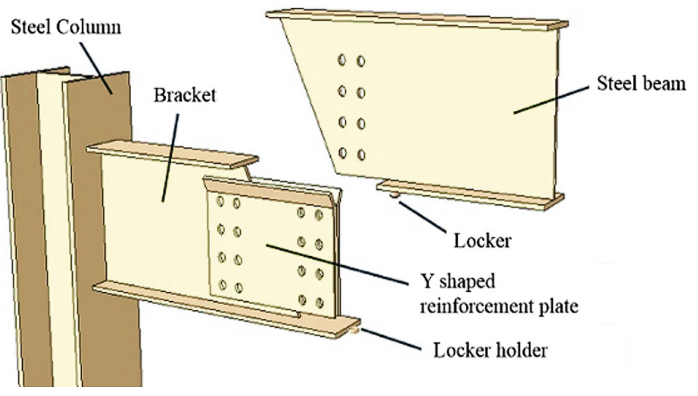

Fig. 7. Y-shaped reinforcement plate for easy connection

steel web. Once the steel beam is led into the Y-shaped reinforcement plate by a crane, it slides along the slope via the gravitational load of the steel beam (Yang et al. 2009). The bolting work is performed when the locker attached to the bottom of the steel beam penetrates the locker holder attached to the bottom of the bracket. This connection method was developed for the quick installation of $\mathrm{H}$-steel, and uses the beam-side bottom flange that is set back to avoid interference between the Y-shaped reinforcement plates and the bottom flange of the steel beam during installation. Although this method improves the productivity of the steel frame work, elaborate steel manufacturing efforts are required to build these connections and their inclusion results in increased cost.

The use of T-type (or reverse T-type) steel connections in the beam side of the Green Frame, shown in Figure 1, eliminates interference from flanges, and results in a simplified connection method. This method, as proposed in the current study, can secure structural stabilities and improve constructability.

\section{Steel-guide connection method for CPC components}

\subsection{Solution for horizontal eccentricity $\left(e_{h}\right)$}

The axial eccentricity introduced in Figure 3 can be solved by the use of L-shaped, or unequal leg angle, reinforcement plates with rounded corners, as shown in Figure 8.

As introduced in Figure 6, unlike the separate reinforcement plates applied to the flange and web in existing steel connections, L-shaped plates can be used to reinforce both the flange and web simultaneously. When such reinforcement plates are used, it is much easier to address

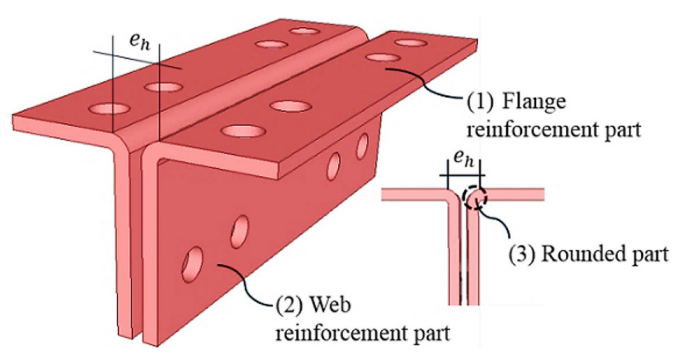

Fig. 8. Reinforcement plate to solve horizontal eccentricity 


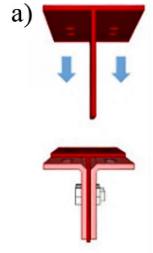

b)

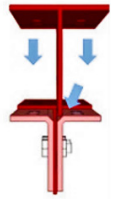

c)

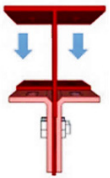

d)

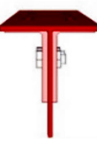

e)

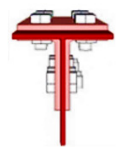

Fig. 9. Installation process of L-shaped reinforcement plate

axial eccentricity, as demonstrated in Figure 9. The role of the shape of the reinforcement plate is follows: (1) The flange reinforcement performs a temporary, safe receipt of the beam's web steel in the reinforcement plates when an axial eccentricity of beam occurs while approaching the beam, as shown in Figure 3. Furthermore, it supports the weight of the beam once the beam reaches the installation location; (2) The web reinforcement acts as a guide to axially align the column and beam steel, leading it to the installation location along the web; (3) The rounded corner of the reinforcement plates slide and set the beam steel inside the reinforcement plate along the slope, due to the gravitational load of the beam. The span between the rounded corners covers the horizontal eccentricity $\left(e_{h}\right)$. The sliding and setting concept of this paper is derived from the concept of designing compliance into the parts, which allows them to fit together when misaligned (Kusiak 1990).

The existing steel frame work is unstable because the columns and beams are fabricated using separate plates for the flange and web. However, if the reinforcement plate designed in this study is applied, stability problems can be eliminated since the flange and web reinforcements are formed as a single body.

\subsection{Solution for vertical eccentricity $\left(e_{v}\right)$}

In order to solve the column eccentricity specified in Figure 5, the method of using the slope steel as shown in Figure 10 is proposed. According to the structural design of numerous case projects, the CPC beam in the Green Frame was $0.35 \mathrm{~m}$ (width) $\times 0.25 \mathrm{~m}$ (depth) $\times 4.2 \sim 6.3 \mathrm{~m}$ (length) in size, and in most cases had dimensions of

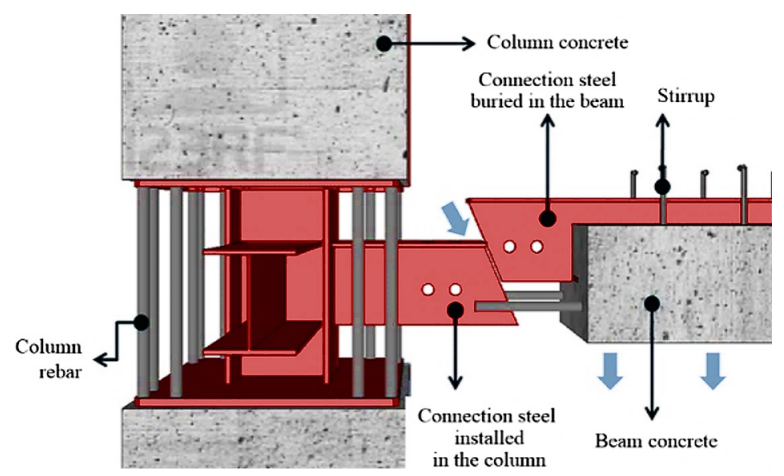

Fig. 10. Sloped steel connection of CPC beams
$0.35 \times 0.25 \times 5.5 \mathrm{~m}$. The beam weight was typically below 1.1 tons, with a maximum weight of 1.5 tons (Joo et al. 2012). Thus, when the connection steels of the columns and beams are designed using the slope, the gravitational load of the beams generates the force to push the column along the slope, making it slide along the slope and securing the installation space (Lim et al. 2012).

\subsection{Connection process of CPC beams}

As described above, the use of a reinforcement plate resolves the axial eccentricity $\left(e_{h}\right)$ between the column and the beam steel connection, and the slope of the connection steel resolves the column axis eccentricity $\left(e_{v}\right)$. The reinforcement plate designed in this study is installed in various locations, depending on the CPC beam type (T-type or reverse T-type). As shown in Figure 11(a), the reinforcement plate used in the T-type is pre-installed in the column, so that it does not interfere with the sliding of the upper flange. As shown in Figure 11(b), the reinforcement plates used in the reverse T-type are pre-installed at both ends of a beam with reverse direction to avoid interference with the sliding of the bottom flange. Because the process of reinforcement plate installation is skipped, these steps decrease installation time.

As mentioned above, the Green Frame steel is either the T-type or reverse T-type, and the L-shaped reinforcement plate is pre-installed to the connection steel in the column or beam side. As illustrated in Figure 9(b), the connection steel between a column and a beam is aligned to the same horizontal axis by the rounded corner of the reinforcement plate. As shown in Figure 9(d), the beam then slides via the sloped steel section and reaches the correct position, guided by the web of reinforcement plates. In other words, when the beam approaches to the upper part of reinforcement plate, sliding is used for a quick, convenient connection.

In existing steel connection, the crane wire cannot be disconnected from the hanging beams until the components are installed and connected by reinforcement plates and bolts. The reinforcement plate designed in this study performs temporary saddling without bolting, making it a) T type
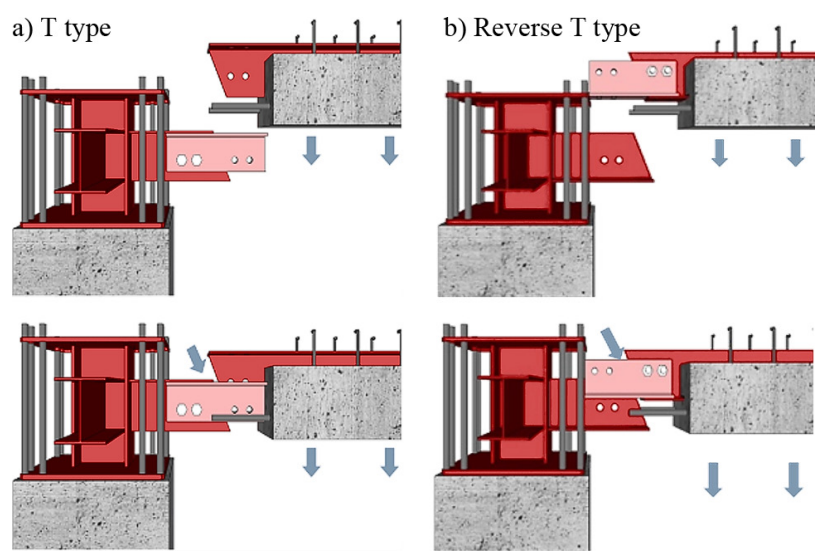

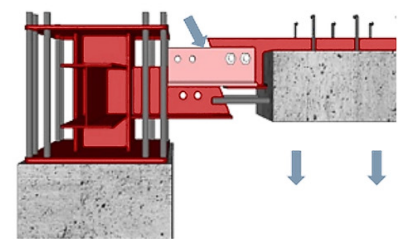

Fig. 11. Connection process of CPC beams 


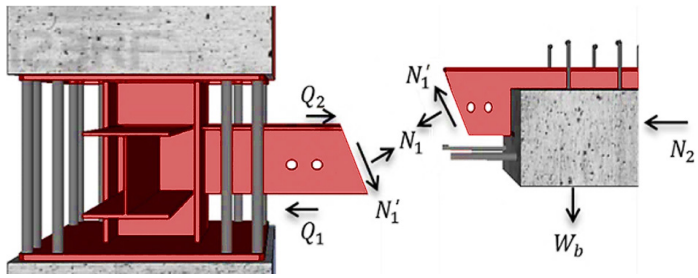

Fig. 12. Structural mechanism of connection steels

capable of supporting the beam load. Thus, since the adjusting and bolting times for temporary connection are omitted in the erection process, the wire can be disconnected without bolting when components reach the installation location. As a result, the PC components can be safely installed, and the time required for beam installation can be shortened.

\section{Slope analysis of connection steels}

The CPC beams of the Green Frame are designed in a wide range of sizes. When the SCM developed in this study is applied in practice, the slope of the connection steel, depending on the gravitational load of the CPC beams, should be determined via the engineering calculation. It is an extremely time consuming effort to calculate the slope of connection steel for each beam size. Thus, the slopes of the connection steels must be analyzed as described below for an easy, quick reflection in the engineering design stage.

\subsection{Free-body diagram}

The conditions for calculating the slope angle of the connection steel are as follows. First, the slope angle $(\theta)$ of a steel should be greater than $0^{\circ}$ and less than a right angle $\left(90^{\circ}\right)$, as shown in Figure 13. Second, the reaction force of the connection steel $\left(Q_{2}\right)$ based on the gravitational load of the beams should be equivalent to or greater than the axial force acting at the connection steels $\left(Q_{1}\right)$ which required to restore the eccentricity $\left(e_{v}\right)$.

The free-body diagram shows all forces acting on a given object (Beer et al. 2008). Therefore, Figure 12 can be simplified to draw a free-body diagram, as shown in Figure 13. The variables applied for the slope analysis of connection steels are listed in Table 1.

\subsection{Free-body diagram of a beam steel}

The free-body diagram showing the connection of the steel of a beam and the direction of force acting on it is

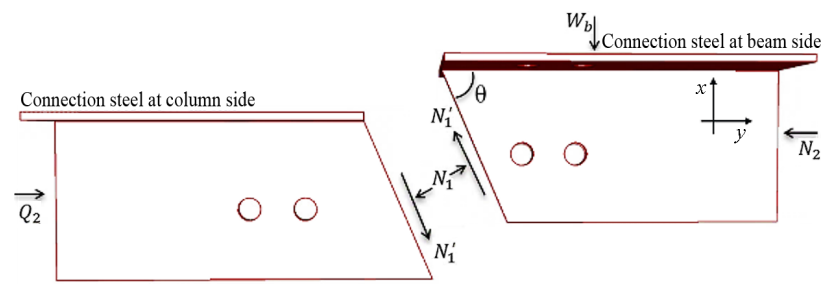

Fig. 13. Free-body diagram of connection steels
Table 1. Variables for slope analysis of connection steels

\begin{tabular}{c|l|c|l}
\hline Variables & Contents & Variables & Contents \\
\hline$\theta$ & $\begin{array}{l}\text { Slope angle } \\
\text { of connection } \\
\text { steels }\end{array}$ & $W_{b}$ & $\begin{array}{l}\text { Gravitational } \\
\text { weight of CPC } \\
\text { beams }\end{array}$ \\
\hline$N_{1}$ & $\begin{array}{l}\text { Reacting force } \\
\text { of column } \\
\text { steels }\end{array}$ & $N_{1}$, & $\begin{array}{l}\text { Frictional } \\
\text { force acting at } \\
\text { connection steels }\end{array}$ \\
\hline$N_{2}$ & $\begin{array}{l}\text { Equilibrium } \\
\text { force acting at } \\
\text { CPC beams }\end{array}$ & $e_{v}$ & $\begin{array}{l}\text { Displacement of } \\
\text { CPC columns }\end{array}$ \\
\hline$Q_{2}$ & $\begin{array}{l}\text { Floor height } \\
\text { of connection } \\
\text { steels }\end{array}$ & $Q_{1}$ & $\begin{array}{l}\text { Axial force acting } \\
\text { at connection steels }\end{array}$ \\
\hline$E_{C}$ & $\begin{array}{l}\text { CPC columns' } \\
\text { elastic modulus }\end{array}$ & $I_{g}$ & $\begin{array}{l}\text { Frictional factor of } \\
\text { steel }\end{array}$ \\
\hline
\end{tabular}

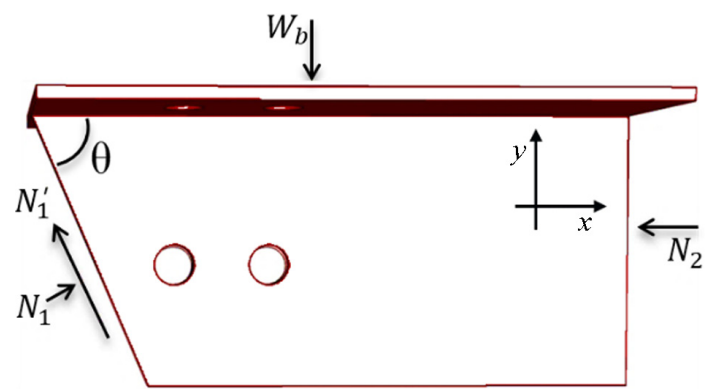

Fig. 14. Free-body diagram of beam steel

shown in Figure 14. The component forces of the frictional force acting on the beam side for the reaction force of the column steel $\left(N_{1}\right)$ and the frictional force acting on the connection steel $\left(N_{1}{ }^{\prime}\right)$ are shown in Figure 15. For such a force, Eqn (1) represents the reaction force of column steel $\left(N_{1}\right)$, using the equation of equilibrium for the y axis. When Eqn (1) is resolved for $N_{1}$, it will be represented as Eqn (2):

$$
\begin{gathered}
\Sigma F_{y}=0 ; N_{1} \cos \theta+\mu W_{b} \sin \theta-W_{b}=0 ; \\
N_{1}=\frac{W_{b}}{\cos \theta+\mu \sin \theta},
\end{gathered}
$$

where: $N_{1}$ - reacting force of column steels; $\theta$ - slope angle of connection steels; $\mu$ - frictional factor of steel; $W_{b}$ - gravitational weight of CPC beams.

\subsection{Free-body diagram of a column steel}

The free-body diagram of the connection steel of a column and the direction of the forces acting on it is shown in Figure 16. The component forces of the frictional force acting on the column side for the reaction force of column steel $\left(N_{1}\right)$ and the frictional force acting on the connection steel $\left(N_{1}{ }^{\prime}\right)$ are shown in Figure 17. Eqn (3) repre- 


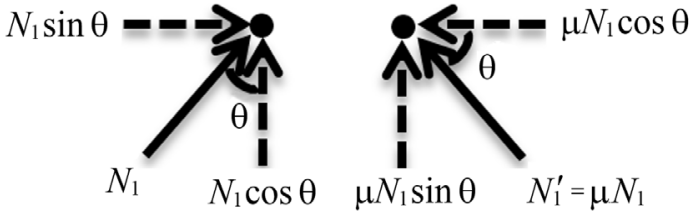

Fig. 15. Component forces of a frictional force acting on the beam side

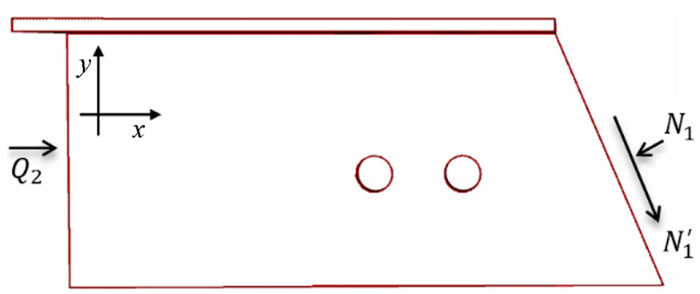

Fig. 16. Free-body diagram of column steel

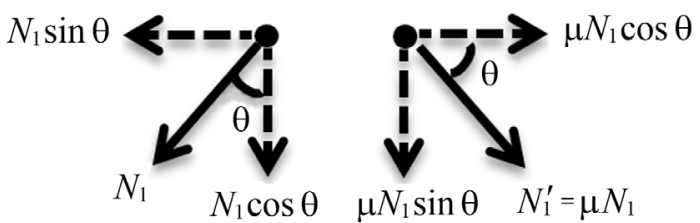

Fig. 17. Component forces of a frictional force acting on the column side

sents the reaction force in the connection steels $Q_{2}$, using the equation of equilibrium for the $\mathrm{x}$ axis. When Eqn (3) is resolved for $Q_{2}$, it will be represented as Eqn (4). When Eqn (2) is applied to the $N_{1}$ of Eqn (4), it will be equivalent to Eqn (5):

$$
\begin{gathered}
\Sigma F_{x}=0 ; Q_{2}+\mu N_{1} \cos \theta-N_{1} \sin \theta=0 ; \\
Q_{2}=N_{1}(\sin \theta-\mu \cos \theta) ; \\
Q_{2}=W_{b} \frac{(\sin \theta-\mu \cos \theta)}{(\cos \theta+\mu \sin \theta)},
\end{gathered}
$$

where $Q_{2}$ - reacting force of connection steels.

\subsection{Relationship of column eccentricity and slope}

The axial force caused by the gravitational load of the beams generates eccentricity $\left(e_{v}\right)$ in the columns, as shown in Figure 5. Suppose that the column bottom is the fixed end. Eccentricity $\left(e_{v}\right)$ in the column, which shall be restored by axial force acting at the connection steels $\left(Q_{1}\right)$ via the beam load, is similar to the deflection of the cantilever. Thus, when Eqn (6), an equation used to calculate the deflection of the cantilever, is used to resolve the axial force $\left(Q_{1}\right)$ to restore the eccentricity $\left(e_{v}\right)$, it will be equivalent to Eqn (7):

$$
e_{v}=\frac{Q_{1} H^{3}}{3 E_{c} I_{g}}
$$

$$
Q_{1}=\frac{3 E_{c} I_{g} e_{v}}{H^{3}}
$$

Based on the second constraint condition, the axial force $\left(Q_{1}\right)$ required to restore the eccentricity $\left(e_{v}\right)$ should be equivalent to or bigger than the axial force caused by the gravitational load of the beams $\left(Q_{2}\right)$ in Eqn (5). Thus, Eqn (8) can be represented with Eqns (5) and (7):

$$
\frac{3 E_{c} I_{g} e_{v}}{H^{3}} \geq W_{b} \frac{(\sin \theta-\mu \cos \theta)}{(\cos \theta+\mu \sin \theta)},
$$

where $e_{v}$ - displacement of CPC columns; $Q_{1}$ - axial force acting at connection steels; $H$ - floor height; $E_{c}$ CPC columns' elastic modulus; $I_{g}$ - moment of inertia of CPC column.

The purpose is to obtain $\theta$ for practical applications in various situations, yet Eqn (8) could not be resolved for $\theta$. If a numerical simulation using a computer is adopted, however, the approximate value of $\theta$ can be achieved.

\subsection{Slope analysis of connection steels}

The size and length of column and beam sections can be combined in various ways depending on the project characteristics and site conditions. The use of Eqn (8) to calculate the approximate slope value each time is difficult onsite; therefore, the slope using the beam length and column size frequently designed, based on the beam with the smallest sectional size, is proposed. The variables used for calculation are shown in Table 2.

The unit weight of typical reinforced concrete is $2,400 \mathrm{~kg} / \mathrm{m}^{3}$; however, since the connection steel is buried in the beam of the Green Frame, its unit weight is assumed to be $2,500 \mathrm{~kg} / \mathrm{m}^{3}$. There is no local regulation regarding the vertical eccentricity of columns $\left(e_{v}\right)$. According to the Japanese Architectural Standard Specification (JASS 1 2002), the allowable eccentricity of columns is $\pm 6 \mathrm{~mm}$ per $3 \mathrm{~m}$. The displacement caused by the gravitational load of beams is calculated using the slopedeflection equation, based on the displacement method, and gives a result of less than $0.001 \mathrm{~mm}$, which is small enough that it can be ignored. Therefore, the displacement value for standard slope calculations is assumed to be $6 \mathrm{~mm}$. Since the displacement value is applied to both

Table 2. Applied variables

\begin{tabular}{l|l|l|l}
\hline Variables & $\begin{array}{l}\text { Assigned } \\
\text { values }\end{array}$ & Variables & $\begin{array}{l}\text { Assigned } \\
\text { values }\end{array}$ \\
\hline Floor height & $2.9 \mathrm{~m}$ & $\begin{array}{l}\text { Compressive } \\
\text { strength }\end{array}$ & $26 \mathrm{MPa}$ \\
\hline $\begin{array}{l}\text { Frictional } \\
\text { factor of steel }\end{array}$ & 0.42 & $\begin{array}{l}\text { Unit weight } \\
\text { of beam }\end{array}$ & $2,500 \mathrm{~kg} / \mathrm{m}^{3}$ \\
\hline $\begin{array}{l}\text { Section size } \\
\text { of beam }\end{array}$ & $\begin{array}{l}0.35 \mathrm{~m} \times \\
0.25 \mathrm{~m}\end{array}$ & Column size & $\begin{array}{l}0.4 \mathrm{~m} \times 0.4 \mathrm{~m} \sim \\
0.6 \mathrm{~m} \times 0.6 \mathrm{~m}\end{array}$ \\
\hline $\begin{array}{l}\text { Length of } \\
\text { beam }\end{array}$ & $4.5 \sim 8 \mathrm{~m}$ & & \\
\hline
\end{tabular}


ends of the beams, a column axis eccentricity of up to $12 \mathrm{~mm}$ can be solved. Although the compressive strength of concrete is typically high, the most commonly used value of $26 \mathrm{MPa}$ is applied with an assumed floor height of $2,900 \mathrm{~mm}$. Since this is based on the beam with the smallest section, the beam size is taken to be $350 \mathrm{~mm}$ (width) $\times 250 \mathrm{~mm}$ (depth). The slope per CPC beam size calculated via numerical simulation using a computer is shown in Table 3. Table 3 for the practical selection of slope angles were presented with the beam spans and column sizes of frequently used in practices.

Table 3. Slope analysis of connection steels

\begin{tabular}{|c|c|c|c|c|c|c|c|c|}
\hline $\begin{array}{l}\text { Beam span } \\
\text { Column } \\
\text { size }(\mathrm{mm})\end{array}$ & 4.5 & 5 & 5.5 & 6 & 6.5 & 7 & 7.5 & 8 \\
\hline $400 \times 400$ & 50 & 48 & 46 & 44 & & & & \\
\hline $450 \times 450$ & & 60 & 58 & 55 & 53 & & & \\
\hline $500 \times 500$ & & & 69 & 67 & 65 & 62 & & \\
\hline $550 \times 550$ & & & & 78 & 75 & 73 & 71 & \\
\hline $600 \times 600$ & & & & & 84 & 83 & 81 & 79 \\
\hline
\end{tabular}

The weight of the beam increases with beam size. In turn, the axial force $\left(Q_{1}\right)$ that restores the eccentricity $\left(e_{v}\right)$ increases. Also, according to Eqn (5), if $\theta$ increases, $Q_{2}$ also increases; therefore, the slope proposed in Table 3 is the minimum value under the given conditions, and can be applied even when the bean section increases in size.

\section{Conclusions}

In the installation process of column-beam structures such as Green Frame, eccentricities are often caused by the gravitational load of beams and construction errors. Such problems lead to installation delays and decreased productivity. We developed the Steel-guide Connection Method for composite precast concrete components to address these issues. The conclusions as part of the characteristics of SCM was drawn as follows

First, the SCM reinforcement plate is used to restore the axial eccentricity $\left(e_{h}\right)$ between column and beam. The rounded corners of the reinforcement plates slide and set the beam steel inside the reinforcement plate along the slope, based on the beam's gravitational load, covering horizontal eccentricity $\left(e_{h}\right)$. And the reinforcement plates introduced in this paper will also be used as web stiffeners after they served as sliding guide plates, saving additional installation time.

Second, the column and beam connection steel is then designed as a slope to restore the column axis eccentricity $\left(e_{v}\right)$. The gravitational load of the beams generates the force to push the column along the slope, securing the installation space.

Third, the flange of the reinforcement plate is designed to support the gravitational and construction loads of the beams, leading to a reduction in installation time.
Finally, the slope of connection steel is suggested depending on member size, as shown in Table 3, via analysis of the construction and the structural characteristics of SCM. Using the slope on the table, SCM can be easily and quickly applied at the design stage.

When the SCM proposed in this study is used for installation, one CPC beam can be installed within a minute. When the SCM proposed in this study is used for installation, one CPC beam can be installed within 3.45 minutes including one minute of setting time to CPC column.

In the case of a 20 story apartment building that has 1,060 beams with 53 beams per each floor, it will take 8.21 hours for the beam installation of each floor and 164.12 hours for the entire building, considering the average installation time of a steel beam by 9.29 minutes with the existing method (Kim 2011). However, it takes 3.05 hours for each floor and 60.95 hours for the entire building with the steel-guide connection proposed in this study. The simulation result of the case building shows that the proposed method is proven to be innovative in reducing not only the time by 106.17 hours, $62.9 \%$ of the total time of the existing method, but also the corresponding cost for equipment and labor.

Further analysis is needed, related to installation time and cost when this is applied to an entire building. Scientific analysis of the productivity of the proposed SCM is also recommended, and should be reflected in the construction plan.

\section{Acknowledgements}

This research was supported by the Ministry of Land, Infrastructure and Transport (MOLIT) of the Korea government and the Korea Agency for Infrastructure Technology Advancement (KAIA) (No. 13AUDP-B068892-01).

\section{References}

Bang, S. W.; Kim, J. H.; Lim, N. G. 2003. The improvement plan of design process by case study of steel structural work, Journal of the Korea Institute of Building Construction 3(2): 111-118.

http://dx.doi.org/10.5345/JKIC.2003.3.2.111

Beer, F.; Johnston, E. R. Jr.; Mazurek, D. 2008. Vector mechanics for engineers-statics. McGraw-Hill. $656 \mathrm{p}$.

Hong, W. K.; Kim, J. M.; Park, S. C.; Lee, S. G.; Kim, S. I.; Yoon, K. J.; Kim, H. C.; Kim, J. T. 2009. A new apartment construction technology with effective $\mathrm{CO} 2$ emission reduction capabilities, Energy 35(6): 2639-2646. http://dx.doi.org/10.1016/j.energy.2009.05.036

Hong, W. K.; Kim, S. K.; Kim, H. K.; Yoon, T. H.; Yune, D. Y.; Kim, S. I. 2010a. A feasibility study of Green Frame (GF) for the implementation of low-carbon emissions \& long-life housing, Journal of the Korea Institute of Building Construction 10(1): 57-63. http://dx.doi.org/10.5345/JKIC.2010.10.1.057

Hong, W. K.; Park, S. C.; Kim, J. M.; Kim, S. I.; Lee, S. G.; Yune, D. Y.; Yoon, T. H.; Ryoo, B. Y. 2010b. Development of structural composite hybrid systems and their application with regard to the reduction of $\mathrm{CO} 2$ emissions, Indoor and Built Environment 19(1): 151-162. http://dx.doi.org/10.1177/1420326X09358142 
JASS 1. Japanese Architectural Standard Specification JASS 1 General. Japanese Standard Association, 2002. 66 p.

Joo, J. K.; Kim, S. E.; Lee, G. J.; Kim, S. K.; Lee, S. H. 2012. A study on the lifting progress for composite precast concrete members of Green Frame, Journal of the Korea Institute of Construction Engineering and Management 13(3): 34-42. http://dx.doi.org/10.6106/KJCEM.2012.13.3.034

Kim, C. K. 2011. Steel-joint improvement and field applicability evaluation for automated building construction. Korea: Korea University. 225 p.

Kim, D. K.; Yang, S. W.; Kim, T. H.; Shin, Y. S.; Cho, H. H.; Kang, K. I. 2009. Constructability analysis of self-supported steel joint for automated construction system, in Proc. of the Korea Institute of Building Construction, 2009, the Korea Institute of Building Construction, Seoul, Korea, $1-4$.

Kim, K. H.; Lee, D. H.; Kim, S. K. 2013. A basic study of steel-joint connection method of composite precast concrete members, Journal of the Korea Institute of Building Construction 13(1): 10-11.

Kusiak, A. 1990. Intelligent manufacturing systems. Prentice Hall. 443 p.

Lee, S. H.; Joo, J. K.; Kim, J. T.; Kim, S. K. 2012. An analysis of the $\mathrm{CO} 2$ reduction effect of a column-beam structure using composite precast, Indoor and Built Environment 21(1): 150-162. http://dx.doi.org/10.1177/1420326X11423162
Lee, S. H.; Kim, S. E.; Kim, G. H.; Joo, J. K.; Kim, S. K. 2011. Analysis of structural work scheduling of Green Frame focusing on apartment buildings, Journal of the Korea Institute of Building Construction 11(3): 301-309. http://dx.doi.org/10.5345/JKIC.2011.06.3.301

Lim, C. Y.; Joo, J. K.; Lee, G. J.; Kim, S. K. 2011. Requirement analysis for development of the bolt-type rebar coupler, in Proc. of the Korea Institute of Building Construction, 2011, the Korea Institute of Building Construction, Suwon, Korea, 169-170.

Lim, C. Y.; Kim, K. H.; Na, Y. J.; Kim, S. K. 2012. Conceptual study for improvement of connection between precast concrete members, Journal of the Architectural Institute of Korea (Academic Conference of Spring) 32(1): 169-170.

Seo, S. Y.; Yoon, S. J.; Lee, W. J. 2008. Evaluation of structural performance the hollow PC column joint subjected to cyclic lateral load, Journal of the Korea Concrete Institute 20(3): 335-343. http://dx.doi.org/10.4334/JKCI.2008.20.3.335

Yang, S. W.; Kim, T. H.; Cho, H. H.; Kang, K. I. 2009. Deducing criteria for safety performance evaluation of selfsupported steel joint for construction automation, in Proc. of the Korea Institute of Construction Engineering and Management, 2009, the Korea Institute of Construction Engineering and Management, Daejeon, Korea, 479-482.

Won-Kee HONG. PhD, P.E. Is currently in charge of research projects supported by Korean government including the Technology Transfer Center for National R\&D Program (TTC) and Korea Agency for Infrastructure Technology Advancement (KAIA) for the practical application of Smart Green Frames. For over ten years, Dr. Hong has been developing innovative hybrid Smart Green Frames that can replace conventional structural frames. He has also developed and registered US patents for many other construction methods which replaced the conventional method, showing his contributions to the industry of the country.

Gyeongju KIM. Is a student of MSc course and a research assistant at the department of Architectural Engineering, Kyung Hee University. Her research area is the development of innovative construction technology including engineering details and management techniques. She published two papers in the conferences and applied for one patent of free-form concrete production technology as a co-inventor. She is a member of SMART SPACE laboratory at Kyung Hee University.

Chaeyeon LIM. PhD student. Is a research assistant at the department of Architectural Engineering, Kyung Hee University. His research area is the development of innovative construction technology including engineering details and management techniques. He published three papers in the international journals and seventeen papers in the international conferences in the construction engineering and management. He has also developed and registered four patents of new construction methods as a co-inventor.

Sunkuk KIM. PhD, P.E. Is a leader of the innovative construction technology and management system. Currently, he has served as a vice director of the Centre for Sustainable Healthy Buildings and a vice president of Korean Council on Tall Buildings and Urban Habitat (K-CTBUH). His research interests include the construction engineering and management issues, particularly the development of innovative practical construction technologies such as the Green Frame, a sustainable environment-friendly structure, and the production technology of free-form concrete segments. 